\title{
A Case Report on Bartter Syndrome as Urinary Tract Stone and Poor Weight Gain in a One-Year Old Child
}

\author{
Alia Jalalodini (iD ${ }^{1,}{ }^{*}$ and Hamideh Goli ${ }^{2}$ \\ ${ }^{1}$ Community Nursing Research Center, Faculty of Nursing and Midwifery, Zahedan University of Medical Sciences, Zahedan, Iran \\ ${ }^{2}$ Faculty of Nursing and Midwifery, Sabzevar University of Medical Sciences, Sabzevar, Iran \\ "Corresponding author: Community Nursing Research Center, Faculty of Nursing and Midwifery, Zahedan University of Medical Sciences, Zahedan, Iran. Email: \\ a_jalalodini@yahoo.com
}

Received 2018 November 10; Accepted 2018 November 24.

\begin{abstract}
Introduction: Bartter syndrome (BS) is a rare metabolic disorder causing defect in sodium and chloride absorption in the thick ascending limb of Henle's loop and increased urinary loss of sodium chloride ( $\mathrm{Na}$ ), chloride (Cl), and prostaglandins.

Case Presentation: We present the case of a 1-year-old girl with BS presenting with vomiting, poor feeding, and agitation. Physical examination revealed muscle weakness, developmental delay, and failure to thrive. Laboratory investigations revealed hypokalemia, metabolic alkalosis, hyponatremia, and hypokalemia. Urinary investigations revealed raised urinary chloride, sodium, potassium, and calcium levels. Renal ultrasound revealed a renal calculus in the lower calyx of the right kidney with hydronephrosis.

Conclusions: The basic defect in BS is the loss of one of the transporters involved in sodium reabsorption in the thick ascending limb on the Henle's loop or apical K channel. BS is characterized by severe hypokalemia, metabolic alkalosis, hyponatremia, hypochloremia, and hyperaldosteronism. In BS, increased urinary loss of sodium, potassium, and chloride is observed.
\end{abstract}

Keywords: Bartter Syndrome, Urinary Calculi, Failure to Thrive, Hypokalemia

\section{Introduction}

Bartter syndrome (BS) is a rare metabolic disorder affecting sodium and chloride absorption in the thick ascending limb of Henle's loop (1) and causing increased urinary loss of sodium chloride $(\mathrm{Na})$, chloride $(\mathrm{Cl})$, and prostaglandins $(2,3)$.

BS involves renal tubular system and is characterized by severe hypokalemia, metabolic alkalosis, hyponatremia, hypochloremia, hyperaldosteronism, and increased urinary loss of sodium, potassium, and chloride (4-7).

Mothers of fetuses with BS often present with elevated amniotic fluid chloride and polyhydramnios secondary to intrauterine polyuria. Also, this disorder is accompanied by growth retardation, premature delivery, hypercalciuria, and nephrocalcinosis during gestation (8).

The classic signs of BS in early childhood include salt craving, polyuria, vomiting, generalized weakness, constipation, lethargy, muscle weakness, muscle spasm, and failure to thrive (FTT) $(2,8,9)$.

We present in this case report an unusual case of BS with urinary tract stone and poor weight gain.

\section{Case Presentation}

A 1-year-old girl with BS was admitted to Imam Ali Hospital in Zahedan city, (Sistan and Baluchistan province), Iran due to vomiting and poor feeding since five days ago and agitation in the past 10 days.

The child's vomiting was non-bilious and occurred frequently and 6 - 8 times a day. The pain and agitation of the child led to poor oral intake and insomnia. On physical examination, we observed failure to thrive (FTT). The child weighed $4 \mathrm{~kg}$ with a length of $62 \mathrm{~cm}$. In addition, physical examination revealed loss of muscle tone (muscle weakness) and involuntary movements. Also, the child was not able to lift her head and limbs. Developmental milestones were abnormal. She was unable to walk and started crawling from birth to now. Results of her renal examinations showed kidney stone and hydronephrosis.

Medical history showed history of Bartter syndrome, renal and hematologic system disorders, and urinary stones from two months of age. The child had history of frequent constipation and distention as well.

The child was term and born through vaginal delivery (birth weight: $2760 \mathrm{~g}$ ). The girl was the fourth child of the 
family. Her mother mentioned her cousin had history of renal disorders. Nevertheless, no other family member had a similar illness.

In biochemical and hematologic blood tests, abnormal parameters were as follows, $\mathrm{Hgb}=10, \mathrm{Na}=129, \mathrm{~K}=3$, $\mathrm{MCH}=24.3, \mathrm{MCHC}=30.3$, and $\mathrm{MCV}=78$. As the child had $\mathrm{BS}$, the serum concentrations of $\mathrm{Na}$, chloride, and $\mathrm{K}$ were low. Other laboratory investigations were normal (Table 1). The results of arterial blood gas revealed compensated metabolic alkalosis (Table 2).

Urinary investigation revealed raised urinary chloride (155 mEq/L), sodium (164 mEq/L), potassium (39.1 mEq/L), and calcium $(25.39 \mathrm{mg} / \mathrm{dl})$. Other investigations revealed hematuria and crystal (Table 3 ).

Table 1. The Results of Biochemical and Hematological Blood Tests in a Child with Bartter Syndrome

\begin{tabular}{|c|c|}
\hline Results of Blood Tests in Child & Normal Levels of Blood Parameters \\
\hline $\mathrm{Na}=129 \mathrm{mg} / \mathrm{L}^{\mathrm{a}}$ & $135-145 \mathrm{mg} / \mathrm{dL}$ \\
\hline$K=3 \mathbf{m g} / \mathbf{d L}^{\mathrm{a}}$ & $3.5-5 \mathrm{mmol} / \mathrm{L}$ \\
\hline Chloride $=62 \mathrm{mmol} / \mathrm{L}^{\mathrm{a}}$ & $96-106 \mathrm{mmol} / \mathrm{L}$ \\
\hline $\mathrm{Ca}=10.3 \mathrm{mg} / \mathrm{dl}$ & $9-11.5 \mathrm{mg} / \mathrm{dL}$ \\
\hline Phosphorus $=4.2 \mathrm{mg} / \mathrm{dL}$ & $2.5-5 \mathrm{mg} / \mathrm{dL}$ \\
\hline $\mathrm{WBC}=6000$ & $4000-10000$ \\
\hline PLT $=3870000$ & $150000-400000$ \\
\hline $\mathrm{RBC}=4.12$ & $3.9-5.8$ \\
\hline $\mathrm{Hgb}=10 \mathrm{mg} / \mathrm{dL}^{\mathrm{a}}$ & $11.5-16 \mathrm{~g} / \mathrm{dL}$ \\
\hline Hct $=\mathbf{3 1 . 9}$ & $29-43 \mathrm{~g} / \mathrm{dL}$ \\
\hline $\mathrm{CRP}=96^{\mathrm{a}}$ & Negative \\
\hline$E S R=5 \mathrm{~mm} / \mathrm{h}$ & $0-15 \mathrm{~mm} / \mathrm{h}$ \\
\hline $\mathrm{MCH}=24.3^{\mathrm{a}}$ & $27-32 \mathrm{~g}$ \\
\hline $\mathrm{MCHC}=30.3^{\mathrm{a}}$ & $31-36$ \\
\hline $\mathrm{MCV}=78^{\mathrm{a}}$ & $80-100 \mathrm{fL}$ \\
\hline
\end{tabular}

Abbreviations: Ca, calcium; CRP, creatinine protein; ESR, erythrocyte sedimentation rate; $\mathrm{HCT}$, hematocrit; $\mathrm{Hgb}$, hemoglobin; K, potassium; $\mathrm{MCH}$, mean corpuscular hemoglobin concentration; MCHC, mean corpuscular hemoglobin concentration; $\mathrm{MCV}$, mean corpuscular volume; Na, sodium; RBC, red blood cells; WBC, white blood cell.

${ }^{a}$ Abnormal levels of blood parameters.

Renal ultrasound revealed a renal calculus (measuring $5 \times 3.9 \mathrm{~mm}$ in size) in the lower calyx of the right kidney with hydronephrosis (Figure 1). Her prescribed medications included pedilact oral drop, peditrace vial, syrup potassium chloride, acetylsalicylic acid, and phosphatesandoz.

\begin{tabular}{|c|c|}
\hline Parameters of Arterial Blood Gas & Normal Levels \\
\hline $\mathrm{pH}=7.42^{\mathrm{a}}$ & $7.35-7.45$ \\
\hline $\mathrm{PaCO}_{2}=50^{\mathrm{a}}$ & $35-45 \mathrm{mmHg}$ \\
\hline $\mathrm{HCO}_{3}=30^{\mathrm{a}}$ & $22-26 \mathrm{MEq} / \mathrm{L}$ \\
\hline $\mathrm{PaO}_{2}=79$ & $80-100 \mathrm{mmHg}$ \\
\hline $\mathbf{B E}=+\mathbf{1}$ & $-2,+2 \mathrm{MEq} / \mathrm{L}$ \\
\hline $\mathrm{BB}=42$ & $40-44 \mathrm{MEq} / \mathrm{L}$ \\
\hline
\end{tabular}

a increased.

\begin{tabular}{lc}
\hline Table 3. The Results of Urinalysis in a Child with Bartter Syndrome & \\
\hline Results of Urine Analysis & Amount \\
\hline PH & 6 \\
Blood $^{\mathbf{a}}$ & $(+)$ \\
RBC $^{\mathbf{a}}$ & $12-15$ \\
WBC $^{\mathbf{a}}$ & $3-4$ \\
Crystal $^{\mathbf{a}}$ & $(+)$ \\
Cast $^{\text {Mucus }}$ & $\mathrm{Neg}$ \\
\hline Proteins & $\mathrm{Neg}$ \\
\hline
\end{tabular}

${ }^{\mathrm{a}}$ Abnormal levels of blood parameters.

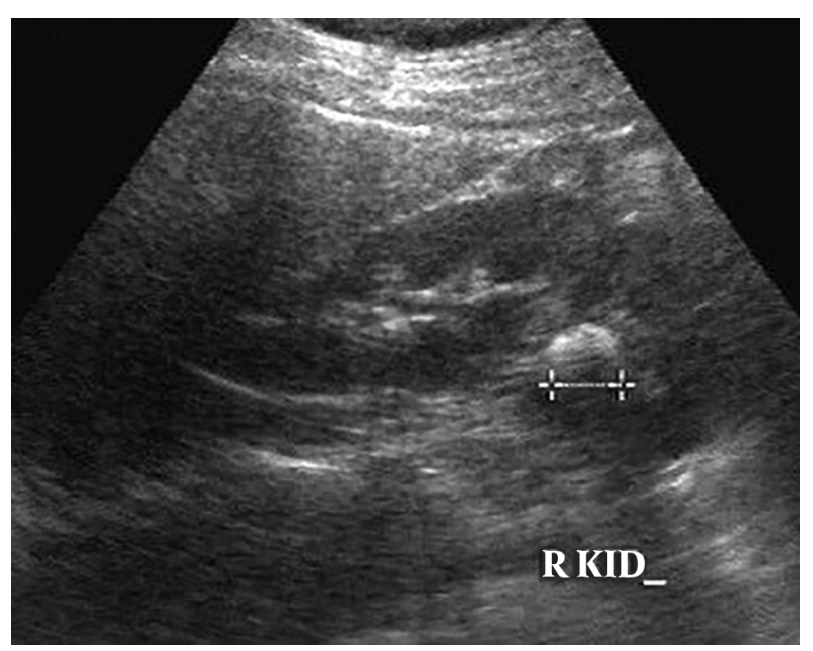

Figure 1. Renal calculus in the lower calyx of the right kidney

\section{Discussion}

BS is an autosomal disorder, which is related to defect of sodium and chloride absorption from the Henle's loop leading to excessive urinary electrolytes loss (10). While loosed absorption of sodium and chloride from the 
Henle's loop, as occurring increased loss of $\mathrm{Na}^{+}, \mathrm{K}^{+}, \mathrm{Cl}^{-}$, and Ca in the urine of patients obviously (2).

The basic defect in BS is loss of one of the transporters involved in sodium chloride reabsorption in the thick ascending limb on the Henle's loop, namely Na-K2CL co-transporter (NKCC2), apical K channel, renal outer medullary potassium channel (ROMK), or basolateral chloride channel $(3,11)$.

BS is recognized as a combination of hyperaldosteronism, hypokalemia, and metabolic alkalosis. Potassium wasting from kidneys may be due to multiple factors leading to hypokalemia. Deficiency of chloride reabsorption in the thick ascending limb of the Henle's loop results in increased sodium concentration in the tubular fluid available for exchange with potassium on reaching the distal tubule. Magnesium wasting and secondary hyperaldosteronism lead to excessive metabolic alkalosis and potassium wasting in this syndrome (11).

Clinical features of BS include poor feeding, weight loss, generalized weakness, muscle weakness, spasm of muscles, short stature, triangular face, prominent forehead, large eyes, protruding ears, drooping mouth, strabismus, and sensorineural deafness $(10,12)$.

FTT is known as inadequate growth or height and weight loss below the third percentile for age on the growth chart. FTT can due to many causes in childhood such as underlying serious systemic diseases. It may occur in the neonatal period with salt wasting (13).

Urinary tract stones are more common in pediatric patients $(14,15)$. Increased levels of calcium and citrate are the risk factors for urinary stones. In children, increased levels of urinary calcium salts lead to calcium-based urinary stones (14). The most common clinical presentation of urinary stones is hematuria and flank or abdominal pain. Stones located in the lower urinary tract may lead to pyuria, dysuria, enuresis, and hematuria, while stones located in the upper urinary tract may cause flank pain, diarrhea, fever, and vomiting $(15,16)$.

In our case, the patient was admitted due to frequent vomiting, poor feeding, and agitation. Physical examination revealed muscle weakness, developmental delay, and FTT. Results of her renal examination showed urinary stone in the lower calyx of the right kidney with hydronephrosis. Blood investigations revealed hyponatremia, hypochloremia, and hypokalemia and the results of urine analysis showed hypercalciuria, raised urinary chloride, and high urinary sodium and potassium levels.

\section{Acknowledgments}

The authors are grateful to the mother and child for their collaboration and the colleagues who helped us in conducting this research.

\section{Footnotes}

Authors' Contribution: Alia Jalalodini: Acquisition and drafting of the manuscript. Hamideh Goli: Study supervision.

Conflict of Interests: There is no conflict of interests. Funding/Support: None.

Patient Consent: Mother's written and verbal consent was obtained after adequate explanations to the subject and mother.

\section{References}

1. Fujino S, Miyoshi N, Ohue M, Mukai M, Kukita Y, Hata T, et al. Rectal Cancer in a Patient with Bartter Syndrome: A Case Report. Genes (Basel). 2017;8(5). doi: 10.3390/genes8050139. [PubMed: 28498361]. [PubMed Central: PMC5448013].

2. Thabet M, Sharaki OA, Fathy HM, Ayoub AZ. clinical and laboratory study of infants and children with bartter syndrome attending Alexandria University Children's Hospital. AlexandrJPed. 2017;30:1-10.

3. Chaitanya K, Jahnavi C, Kanthi Kiran Y, James A, Ashok Kumar TR, Sivakumar T. A case report on neonatal cartter syndrome and it's effective management-clinical pharmacist perspective. Indian $J$ of Pharm Pract. 2015;8(3):133-6.

4. Vora S, Ibrahim T, Rajadurai VS. Maternal pseudo-bartter syndrome associated with severe perinatal brain injury. Indian Pediatr. 2017;54(9):771-3. doi: 10.1007/s13312-017-1173-4. [PubMed: 28984259]

5. Seyberth HW, Schlingmann KP. Bartter- and Gitelman-like syndromes: salt-losing tubulopathies with loop or DCT defects. Pediatr Nephrol. 2011;26(10):1789-802. doi: 10.1007/s00467-011-1871-4. [PubMed: 21503667]. [PubMed Central: PMC3163795].

6. Rumana J, Lyengar A, Maruf-Ul-Quader M, Hanif M. Cystic fibrosis in an infant: Presented as pseudo bartter syndrome Chattagram. Maa-O-Shishu Hospit Med College J. 2016;15(1). doi: 10.3329/cmoshmcj.v15i1.28765.

7. Yalcin E, Kiper N, Dogru D, Ozcelik U, Aslan AT. Clinical features and treatment approaches in cystic fibrosis with pseudoBartter syndrome. Ann Trop Paediatr. 2005;25(2):119-24. doi: 10.1179/146532805X45719. [PubMed: 15949200].

8. Syed Rizwan AB, Abeera M. Bartter syndrome tulane. StatPearls Publishing; 2017.

9. Ramesh Bhat Y, Vinayaka G, Sreelakshmi K. Antenatal bartter syndrome: A review. Inter $J$ of Pediatr. 2012;2012:1-5. doi: $10.1155 / 2012 / 857136$.

10. Choudhary D, Anand VR, Sachdev CP, Gulati D. Hypotonia an unusual childhood presentation of Bartter syndrome. Int J Contemp Pediatr. 2017;4(6):2237-8. doi: 10.18203/2349-3291.ijcp20174766.

11. Sampathkumar K, Muralidharan U, Kannan A, Ramakrishnan M, Ajeshkumar R. Childhood Bartter's syndrome: An Indian case series. Indian J Nephrol. 2010;20(4):207-10. doi: 10.4103/0971-4065.73455. [PubMed: 21206684]. [PubMed Central: PMC3008951].

12. Al-Shibli A, Yusuf M, Abounajab I, Willems PJ. Mixed Bartter-Gitelman syndrome: An inbred family with a heterogeneous phenotype expression of a novel variant in the CLCNKB gene. Springerplus. 2014;3:96. doi: 10.1186/2193-1801-3-96. [PubMed: 24711981]. [PubMed Central: PMC3977018].

13. Ghaljaei F, Goli H, Jalalodini A, Mahmoodi N. Hypophosphatemia dependent rickets with failure to thrive (FTT) in a 4- years old child: Acase report. Int J Pediatr. 2017;5(2):4303-8. doi:10.22038/IJP.2016.7968. 
14. DeFoor W, Jackson E, Schulte M, Alam Z, Asplin J. Calcium-to-Citrate Ratio Distinguishes Solitary and Recurrent Urinary Stone Forming Children. J Urol. 2017;198(2):416-21. doi: 10.1016/j.juro.2017.03.125. [PubMed: 28365270].

15. Akhavan Sepahi M, Hoseini R. [Approach and medical management of uinary tract stone in children Caspian].J of Pediatr. 2016;2(1):86-95. Persian.

16. Rabinowitz R, Hulbert WC, Mevorach RA. Pediatric urology for the primary care physician. New York USA: Humana Press (Springer); 2015. 